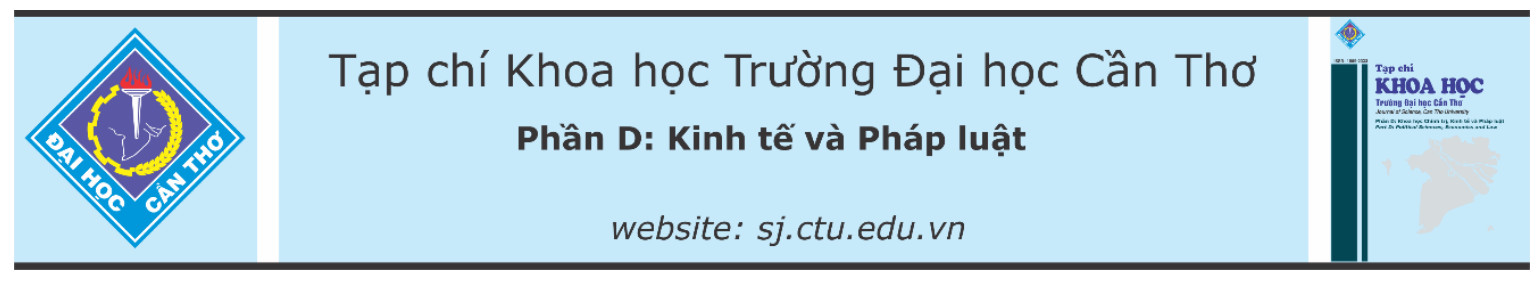

DOI: $10.22144 / c t u . j v n .2021 .164$

\title{
LỰA CHỌN MÔ HİNH SẢN XUẤT CỦA Hộ TRỔNG LÚA TRONG ĐIỀU KIỆN XÂM NHậP MặN: TRƯỜnG HợP CÀ MAU VÀ SÓC TRĂNG
}

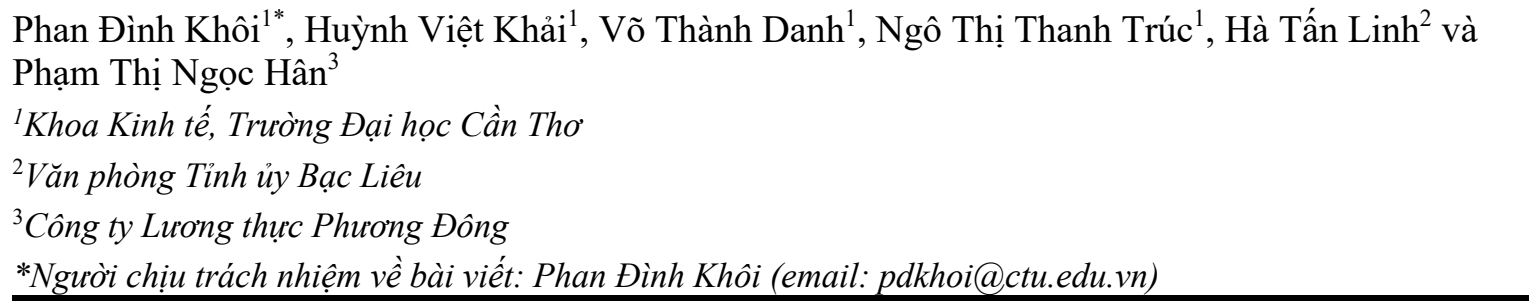

\section{Thông tin chung:}

Ngày nhận bài: 04/05/2021

Ngày nhận bài sưa: 01/07/2021

Ngày duyệt đăng: 29/10/2021

\section{Title:}

Farmers' decision to choose a rice crop model under salinity intrusion: The case of Ca Mau and Soc Trang provinces

\section{Tù khóa:}

Cà Mau, lúa chuyên canh, lúa kết hợp, Sóc Trăng, xâm nhập mạn

\section{Keywords:}

Ca Mau, integrated rice farming, rice monoculture, salinity intrusion, Soc Trang

\begin{abstract}
Salinity intrusion has created great impacts on rice farmers in the coastal provinces in the Mekong River Delta, including Ca Mau and Soc Trang. This paper is to analyze the factors influencing the decision to choose intergraded rice farming systems under saline intrusion conditions by using the Ricardian model. The results revealed that many integrated rice farming systems such as rice-fish, rice-shrimp, and rice-vegetables and others were recorded in the two provinces. The trend of changing from monoculture of 2 and 3 rice crops to integrated rice farming under salinity intrusion conditions was documented at a high rate of over 50 percent. The results also showed that factors affecting rice farmer's choice between rice monoculture and integrated rice farming in Ca Mau and Soc Trang including land area, bank loan status, location, and salinity intrusion. In which, salinity intrusion is the most important factor that directly affects rice farmer's decision to choose intergraded rice farming. This result is consistent with the trend of agricultural restructuring in many other provinces of the Mekong River Delta.
\end{abstract}

\section{TÓM TẮT}

Diễn biến xâm nhập mặn có ảnh hưởng rất lớn đến hộ trồng lúa ở các tỉnh ven biển ở vùng Đông bằng sông Cửu Long, bao gồm Cà Mau và Sóc Trăng. Bài viết này phân tích các yếu tổ ảnh hưởng đến quyết định lựa chọn mô hình canh tác trên đất lúa trong điều kiện xâm nhập mặn dựa vào mô hình Ricardian. Kết quả chỉ ra rằng nhiều mô hình trồng lúa kết hợp nhu lúa cá, lúa tôm, và lúa màu được ghi nhận trên địa bàn của hai tỉnh bên cạn mô hình chuyên canh cây lúa. Xu hướng chuyển đổi tù mô hình trồng lúa chuyên canh 2 vu và 3 vu sang mô hình lúa kết hợp trong điều kiện xâm nhập mặn được ghi nhận với tỉ lệ khá cao trên $50 \%$. Kết quả nghiên cứu còn cho thấy các yêu tố ảnh huởng đến quyết định lưa chọn giữa mô hình sản xuất lúa chuyên canh và mô hình lúa kết hợp của hộ trồng lúa ở Cà Mau và Sóc Trăng bao gồm: diện tích đất, vay vốn, địa bàn và xâm nhập mặn. Trong đó, xâm nhập mặn là yếu tố quan trọng nhất tác động tích cực trục tiếp đến quyết định lựa chọn mô hình sản xuất tù lúa chuyên canh sang lúa kết hợp. Kết quả này phù hơp với xu hướng chuyển dịch cơ cấu nông nghiệp của các tỉnh khác ở trong vìng. 


\section{GIỚI THIẸU}

Diễn biến xâm nhập mặn do biến đổi khí hậu có ảnh hưởng sâu rộng đến hoạt động sản xuất nông nghiệp và đời sống người dân ở Đồng bằng sông Cửu Long (ĐBSCL). Độ mặn lớn nhất diễn ra ở các tuyến sông Tiền và sông Hậu thường xuất hiện vào tháng 4 hoặc tháng 5 trong năm do ảnh hưởng của thủy triều dâng ở bờ biển phía Đông và biển Tây hoặc cùng cả hai. Trong khi đó, lưu lượng nước từ thượng nguồn sông Mê Kông đổ về khu vực hạ lưu giảm; lượng mưa giảm, lượng nước bị bốc hơi nhiều trong mùa khô cũng là những yếu tố góp phần làm cho lượng nước mặn từ biển lấn sâu vào các con sông trong đất liền nhanh hơn. Quá trình thay đổi độ mặn này diễn ra từ lâu theo quy luật tự nhiên nhưng mức độ thay đổi độ mặn gần đây diễn ra ngày rõ ràng hơn hằng năm ở vùng hạ lưu sông Mê Kông thuộc vùng ĐBSCL. Hiện tượng này được các nhà khoa học gọi là hiện tượng xâm nhập mặn. Ngoài những yếu tố tự nhiên có ảnh hưởng đến diễn biến của xâm nhập mặn, khai thác và sử dụng nước ngầm quá mức cũng được cho là nguyên nhân dẫn đến xâm nhập mặn do con người tạo ra.

Xâm nhập mặn ở ĐBSCL được quan sát rõ nhất từ khoảng cuối năm 2015 và những tháng đầu năm 2016, đợt diễn biến xâm nhập mặn này được đánh giá là nặng nề nhất trong 100 năm qua. Trung tâm phòng tránh và giảm nhẹ thiên tai thuộc Bộ Nông nghiệp và Phát triển Nông thôn (Bộ NN\&PTNT) xác định độ mặn 4\%o được coi là bị xâm nhập mặn. Trong khi đó, số liệu đo đạc độ mặn ở sông Tiền và sông Hậu cho kết quả trên $45 \%$, độ mặn này kéo dài và xâm nhập sâu tới $70 \mathrm{~km}$ tính từ cửa sông, thậm chí có thời điểm độ mặn xâm nhập sâu đến $85 \mathrm{~km}$ (Hà Anh, 2016).

Gần đây, diễn biến xâm nhập mặn năm 2019 2020 đã ảnh hưởng đến 10 trên 13 tỉnh ở ĐBSCL, ranh giới độ mặn 4 gam/lít đã làm 42,5\% diện tích tự nhiên của toàn vùng bị ảnh hưởng, tương đương 1.688.600 ha, diện tích bị ảnh hơn cao hơn nhiều so với diện tích bị ảnh hưởng của năm 2016 là 50.376 ha. Các tỉnh gồm Trà Vinh, Tiền Giang, Sóc Trăng, Kiên Giang, Long An, Bến Tre, Bạc Liêu và Cà Mau chịu thiệt hại bởi của xâm nhập mặn với tổng diện tích khoảng 41.900 ha trong vụ Đông Xuân năm 2019-2020. Cà Mau là tỉnh bị ảnh hưởng nặng nhất với diện tích 16.500 ha trên tổng 176.700 ha diện tích gieo trồng trong vụ mùa bị ảnh hưởng, trong đó diện tích lúa bị thiệt hại trắng từ $70 \%$ trở lên là 14.000 ha (Thanh Phong, 2020). Giai đoạn 20162020, có 9 trên 13 tỉnh thành công bố tình trạng thiên tai hạn hán, xâm nhập mặn gồm: Long An, Tiền
Giang, Bến Tre, Trà Vinh, Sóc Trăng, Bạc Liêu, Cà Mau, Kiên Giang, Hậu Giang (Hà Anh, 2016; Thanh Phong, 2020).

Một số giải pháp cấp quốc gia được áp dụng để kiểm soát xâm nhập mặn như: dự án xây dựng hệ thống kênh rạch dẫn nước ở ĐBSCL với quy mô khoảng $5.000 \mathrm{~km}$ kênh rạch được đào khắp các tỉnh, 45 công trình thủy lợi với mục đích giảm thiểu lũ lụt và ngăn mặn, các công trình ngăn mặn tại địa bàn Quản Lộ - Phụng Hiệp, hệ thống thủy lợi ngọt hóa và ngăn mặn ở tỉnh Bến Tre, cống đập $\mathrm{Ba} L a i$ và nhiều công trình ở địa phương đã được triển khai. Tuy nhiên, tình hình xâm nhập mặn vẫn diễn biến phức tạp ở ĐBSCL. Trong đó, Sóc Trăng và Cà Mau là hai tỉnh dễ bị tổn thương bởi xâm nhập mặn do có tỉ lệ hộ trồng lúa và diện tích lúa bị nhiễm mặn lớn nhất trong vùng. Các mô hình trồng lúa chuyên canh 3 vụ lúa hoặc 2 vụ lúa được cho là dễ tổn thương với xâm nhập mặn do nước mặn sẽ kìm hãm sự phát triển sinh lý của cây lúa (Hoang et al., 2016; Gregorio et al., 1997). Do mô hình lúa chuyên canh gặp nhiều rủi ro vì vậy định hướng chuyển đổi các mô hình canh tác lúa kêt hợp thủy sản như một xu hướng tất yếu để thích nghi với điều kiện xâm nhập mặn hiện tại.

Tuy nhiên, kết quả chuyển đổi các mô hình canh tác lúa theo hướng kết hợp chưa được thực hiện rộng rãi ở các địa phương trong vùng ĐBSCL. Bài viêt này nhằm mục tiêu phân tích các yếu tố ảnh hưởng đến quyết định chuyển đổi mô hình canh tác lúa trong điều kiện kiện xâm nhập mặn ở hai tỉnh Cà Mau và Sóc Trăng, hai tỉnh được cho là có ảnh hưởng bởi xâm nhập mặn rất rõ rệt và cũng là hai tỉnh có diện tích lúa chiếm tỉ lệ khá lớn ở vùng ĐBSCL. Dựa vào kết quả ước lượng và thảo luận các yếu tố ảnh hưởng đến quyết định lựa chọn mô hình sản xuất, một số kết luận và hàm ý chính sách về chuyển đổi mô hình sản xuất lúa được đề xuất.

\section{LỰ̛̣C KHẢO TÀI LIỆ}

Nhiều nghiên cứu đánh giá kết quả của các mô hình canh tác trên đất lúa ở ĐBSCL được nghiên cứu trong những năm gần đây. Các nghiên cứu thực nghiệm chỉ ra được ý nghĩa kinh tế của các mô hình sản xuất, góp phần thúc đẩy quá trình chuyển đổi mô hình sản xuất, chuyển dịch cơ cấu sản xuất nông nghiệp. Dựa vào điều kiện sinh thái của từng địa phương, nông hộ chuyển đổi mô hình sản xuất từ lúa chuyên canh sang mô hình lúa kết hợp thủy sản thực nhằm sử dụng tối ưu nguồn tài nguyên đất và nước từ các mô hình trồng lúa sang trồng lúa kết hợp với nuôi trồng thủy sản nhưng không làm mất đi các 
điều kiện tự nhiên phù hợp để trồng lúa trở lại trong năm sau.

Trong điều kiện diễn biến xâm nhập mặn và yêu cầu chuyển đổi mô hình canh tác trên đất lúa, nghiên cứu của Đoàn Thu Hà (2014) cho thấy tỷ lệ hộ trồng lúa bị ảnh hưởng bởi xâm nhập mặn tăng từ 39,5\% tại thời điểm 2012 lên $41,4 \%, 45,3 \%$ và $47,6 \%$ vào các năm 2020, 2030 và 2050 . Tỉ lệ dân số bị ảnh hưởng ngập lũ tăng từ $66,7 \%$ lên $71,9 \%, 74 \%$ và $79,2 \%$ vào các năm 2020,2030 và 2050 . Nguồn nước mặt và nước ngầm đủ cấp trên toàn vùng, nhưng không đều, nhiều vùng khan hiếm nguồn nước. Trong khi đó, Nguyễn Bách Khoa (2015) còn dự báo sẽ có khoảng hơn 300 và 200 ngàn ha diện tích lúa bị ảnh hưởng. Lâm Huôn (2010) chỉ ra rằng xâm nhập mặn ảnh hưởng đến thu nhập của nông hộ, có đến $50,91 \%$ số hộ có thu nhập giảm, đời sống gặp nhiều khó khăn. Vì vậy, xu hướng phát triển đời sống của nông hộ trong thời gian tới nên tập trung vào sản xuất nông nghiệp - thủy sản và phát triển thêm các hoạt động phi nông nghiệp, kinh doanh, và dịch vụ. Ngoài ra, xâm nhập mặn còn phát sinh các vấn đề về chất lượng môi trường buộc nông dân phải lựa chọn các mô hình sản xuất mới như một xu hướng tất yếu để thích nghi với điều kiện xâm nhập mặn hiện tại, cũng như để đảm bảo phát triển nông nghiệp lâu dài và thân thiện với môi trường (Nguyễn Thị Hồng Điệp và ctv., 2017).

Các kết quả nghiên cứu gần đây cho thấy có nhiều mô hình trồng lúa kết hợp đã xuất hiện trong điều kiện biến đổi khí hậu có khả năng thích ứng với môi trường và đem lại hiệu quả cao cho người nông dân góp phần cải thiện đời sống và phần nào làm giảm nhẹ nỗi lo lắng về sự biến đổi bất thường của thời tiết hiện nay (Phạm Thanh Vũ và ctv., 2013). Cụ thể là, kết quả phân tích cho thấy mô hình 2 lúa - 1 đậu nành có hiệu quả kỹ thuật $76,7 \%$ cao hơn mô hình 3 vụ lúa chỉ đạt $67,7 \%$. Mô hình 2 lúa -1 bắp mang lại lợi nhuận cao hơn so với mô hình độc canh 3 vụ lúa 482.000 đồng/1000 $\mathrm{m}^{2}$ (Nguyễn Thanh Giàu, 2009). Ngoài ra, mô hình luân canh lúa - mè đen - lúa có hiệu quả kỹ thuật khá cao đạt ( $\mathrm{TE}=0,913)$, hiệu quả sử dụng chi phí $(\mathrm{CE}=0,818)$, hiệu quả phân phối nguồn lực $(\mathrm{AE}=0,896)$ (Quan Minh Nhựt và ctv., 2014). Hay mô hình luân canh màu trên nền đất lúa cũng mang lại hiệu quả cao, trong đó hai mô hình có hiệu quả kinh tế cao nhất là mô hình lúa - dưa hấu - khoai lang, lúa - dưa hấu (Nguyễn Vương Quốc, 2015).

Không chỉ có các mô hình luân canh lúa màu đem lại hiệu quả cao, mà các mô hình lúa - tôm kết hợp cũng góp phần rất quan trọng trong việc cải thiện sinh kế cho nông hộ. Đặng Thanh Phú (2010) chỉ ra rằng trong các mô hình lúa-tôm ở các tỉnh ven biển ĐBSCL, mô hình lúa - tôm bán thâm canh có chi phí sản xuất cao nhất và mô hình lúa - tôm quảng canh cải tiến có chi phí thấp nhất. So sánh lợi nhuận kinh tế, mô hình lúa- tôm bán thâm canh có lợi nhuận cao nhất, kế đến là mô hình lúa cao sản - tôm bán thâm canh, lúa cao sản - tôm quảng canh cải tiến, và thấp nhất là mô hình lúa - tôm quảng canh cải tiến. So sánh hiệu quả đồng vốn, mô hình canh tác lúa mùa -tôm bán thâm và mô hình lúa cao sản - tôm bán thâm canh có hiệu quả đồng vốn bằng nhau, đồng thời cao hơn hai mô hình canh tác còn lại. Các kết quả nghiên cứu ở ĐBSCL cũng tương đồng với các nghiên cứu ở nước ngoài của Gbetibouo and Hassan (2005), Seo and Mendelsohn (2007) ủng hộ xu hướng chuyển đổi sản xuất thích ứng với điều kiện tự nhiên và chủ động giảm bớt tác động của biến đổi khí hậu của nông dân ở Nam Mỹ.

Tóm lại, sự thay đổi từ mô hình chuyên canh cây lúa sang mô hình kết hợp giúp gia tăng giá trị sản xuất trên diện tích đất lúa ở các tỉnh trong vùng ĐBSCL thông qua ba khía cạnh: (i) tăng năng suất trên đơn vị diện tích lúa thương phẩm có giá trị cao; (ii) giảm nguy cơ dịch bệnh, cải thiện đất; và (iii) thích ứng với điều kiện biến đổi khí hậu, xâm nhập mặn. Điều này đã góp phần to lớn nhằm bảo vệ môi trường và giữ cân bằng sinh thái (Trần Hữu Phúc và ctv., 2007).

\section{PHƯƠNG PHÁP NGHIÊN CÚU}

\subsection{Lý thuyết quyết định lựa chọn mô hình sản xuất}

Lý thuyết giải thích cho quyết định lựa chọn mô hình canh tác của nông hộ dựa theo ý tưởng của nhà kinh tế học David Ricardo (1772-1823) với lập luận rằng giá trị sản xuất được tạo ra từ đất đai phụ thuộc vào năng suất biên của các yếu tố sản xuất. Ý tưởng này được nhiều nhà nghiên cứu dựa vào để xây dựng các mô hình phân tích quyết định sử dụng nguồn lực trong sản xuất của nông hộ (Huong et al., 2019; Lippert et al., 2009; Mendelsohn et al., 1994). Theo đó, mô hình Ricardian bắt đầu với hàm giá trị sản xuất có dạng:

$$
V=\sum P_{i} Q_{i}(X, E)-\sum P_{x} X
$$

Trong đó, $P_{i}$ là giá thị trường của sản phẩm $i$ và $Q_{i}$ là sản lượng của sản phẩm $i ; X$ là các yếu tố đầu vào không bao gồm đất đai và $E$ là các yếu tố liên 
quan đến điều kiện sản xuất; và $P_{\mathrm{x}}$ là giá của yếu tố đầu vào.

Trong điều kiện thị trường cạnh tranh hoàn hảo, nông hộ lựa chọn nguồn lực nhằm tối đa hóa giá trị sản xuất theo điều kiện đóng góp của các yếu tố biên bằng không. Khi đó, hàm giá trị sản xuất được viết lại dưới dạng tuyến tính như sau:

$$
V_{i}=X_{i} \boldsymbol{\beta}+E_{i} \boldsymbol{\varphi}+u_{i}
$$

với $\beta$ và $\boldsymbol{\varphi}$ là các hệ số ước lượng của phương trình (2), $X$ và $E$ được giả định độc lập với sai số $u_{i}$ của mô hình. Ước lượng phương trình (2) dựa vào số liệu thời điểm (cross sectional data) cho phép xác định năng suất biên của các yếu tố sản xuất vào giá trị sản xuất của nông hộ (Gbetibouo \& Hassan, 2005) tuy vậy không cho phép giải thích được quyết định chọn lựa mô hình sản xuất do các quyết định lựa chọn mô hình là đơn nhất và không quan sát trực tiếp được (unobservable, mutually exclusive and exhaustive). Tuy nhiên, xác suất của hộ chuyển đổi có thể được xác định bằng quan sát hiện trạng mô hình canh tác của hộ trong điều kiện các yếu tố giải thích quan sát được. Khi đó, xác suất lựa chọn mô hình sản xuất $j$ với $j \neq k$ thỏa mãn điều kiện: $V_{i j}-V_{i k}>0$, với $k$ là các lựa chọn khác $j$. Một cách tổng quát, McFadden (1974) chứng minh rằng xác suất lựa chọn $j$ được tính bằng công thức sau:

$$
P_{i j}=\frac{e^{X_{i} \boldsymbol{\beta}_{j}+E_{i} \boldsymbol{\varphi}_{j}}}{\sum_{k=1}^{J} e^{X_{i} \boldsymbol{\beta}_{k}+E_{i} \boldsymbol{\varphi}_{k}}}
$$

Trong trường hợp nông hộ lựa chọn chuyển đổi mô hình sản xuất với điều kiện các yếu tố ngoại sinh, phương trình (3) được ước lượng bằng mô hình Probit hoặc Logit với phương pháp ước lượng hợp lý tối đa (MLE).

\subsection{Mô hình ước lượng}

Gọi $j=1$ chỉ hộ chuyển đổi từ mô hình chuyên canh lúa sang mô hình canh tác lúa kết hợp với thủy sản và $j=0$ chỉ các trường hợp không chuyển đổi. Quyết định chuyển đổi mô hình $Y$ của nông hộ phụ thuộc vào các yếu tố độc lập được có dạng:

$$
Y_{i}=\left\{\begin{array}{l}
1 \text { if } V_{i}=V_{j}-V_{k}>0 \\
0 \text { otherwise }
\end{array}\right.
$$

Trong đó, các biến giải thích cho quyết định chuyển đổi từ mô hình chuyên canh lúa sang mô hình kết hợp bao gồm các yếu tố đầu vào $X$ và các yếu tố điều kiện sản xuất $E$. Xác suất của hộ chuyển đổi mô hình canh tác được tính từ phương trình (3) có dạng:

$$
\begin{aligned}
\operatorname{Pr}\left(Y_{i}=1 \mid X, E\right) & =\operatorname{Pr}\left(V_{i}>0 \mid X, E\right) \\
& =\operatorname{Pr}\left(X_{i} \boldsymbol{\beta}+E_{i} \boldsymbol{\varphi}+u_{i}>0\right) \\
& =\operatorname{Pr}\left[u_{i}>-\left(X_{i} \boldsymbol{\beta}+E_{i} \boldsymbol{\varphi}\right)\right] \\
& =\operatorname{Pr}\left(u_{i}<\left(X_{i} \boldsymbol{\beta}+E_{i} \boldsymbol{\varphi}\right)\right) \\
& =\Phi_{i}\left(X_{i} \boldsymbol{\beta}+E_{i} \boldsymbol{\varphi}\right)
\end{aligned}
$$

với $\Phi_{i}($.$) là hàm mật độ phân phối tích lũy (cdf)$ và $\phi_{i}($.$) là hàm mật độ phân phối chuẩn (pdf). Hệ số$ ước lượng $\boldsymbol{\beta}$ và $\boldsymbol{\varphi}$ được ước lượng bằng phương pháp hợp lý tối đa dựa theo Greene (2012). Tuy nhiên, hệ số $\boldsymbol{\beta}$ và $\boldsymbol{\varphi}$ không được sử dụng để giải thích ý nghĩa của các biến độc lập trong mô hình một cách trực tiếp. Vì vậy, tác động biên trung bình $(\mathrm{dy} / \mathrm{dx})$ chỉ ảnh hưởng của các yếu tố độc lập ảnh hưởng đến xác suất chuyển đổi mô hình được tính dựa theo Cameron and Trivedi (2010) và được sử dụng để giải thích ý nghĩa của các biến độc lập trong mô hình thay cho các hệ số ước lượng $\boldsymbol{\beta}$ và $\boldsymbol{\varphi}$ trong mô hình.

Biến phụ thuộc và biến độc lập giải thích cho quyết định lựa chọn mô hình sản xuất từ mô hình lý thuyết Ricardian. Một số biến chỉ đặc điểm chủ hộ, đặc điểm của hộ cũng được đưa vào mô hình ước lượng để kiểm soát cho sự khác biệt giữa các nhóm hộ của các nghiên cứu của Gbetibouo and Hassan (2005), Seo and Mendelsohn (2009) ở nước ngoài; và các nghiên cứu Đoàn Thu Hà (2014), Phạm Thanh Vũ và ctv. (2013) và Quan Minh Nhựt và ctv. (2014) ở Việt Nam. Các biến độc lập trong mô hình cho phép kiểm định 2 giả thuyết được quan tâm sau đây:

\section{Kiểm định giả thuyết 1:}

$\mathrm{H}_{10}$ : Xác suất chuyển đổi mô hình canh tác lúa chuyên canh sang lúa kết hợp không phụ thuộc vào diện tích đất canh tác;

$\mathrm{H}_{1 \mathrm{a}}$ : Xác suất chuyển đổi mô hình canh tác lúa chuyên canh sang lúa kết hợp phụ thuộc vào diện tích đất canh tác.

Kiểm định giả thuyết 2 : 
$\mathrm{H}_{20}$ : Xác suất chuyển đổi mô hình canh tác lúa chuyên canh sang lúa kết hợp không phụ thuộc vào xâm nhập mặn;

Bảng 1. Mô tả biến và dấu kỳ vọng

\begin{tabular}{|c|c|c|}
\hline Tên biến & Ký hiệu & Diễn giải \\
\hline Mô hình sản xuất & Mohinh & $\begin{array}{l}1=\text { lúa kết hợp } \\
0=\text { lúa chuyền canh }\end{array}$ \\
\hline Thu nhập bình quân & Thunhap & Triệu đồng/1.000m²/năm \\
\hline Chi phí bình quân & Chiphi & Triệu đồng/1.000m²/năm \\
\hline Diện tích đất & Dientich & $1000 \mathrm{~m}^{2} / \mathrm{hộ}$ \\
\hline Số nhân khẩu & Nhankhau & Người/hô \\
\hline Số lao động chính & Laodong & Số lao động tham gia sản xuất nông nghiệp (người) \\
\hline Tuối chủ hộ & Tuoi & Tuối của người lao động chính (năm) \\
\hline \multirow{4}{*}{ Trình độ học vấn của chủ hộ } & hocvan1 & $\begin{array}{l}\text { Hoàn thành cấp } 1=1 ; \\
\text { Khác }=0\end{array}$ \\
\hline & \multirow{2}{*}{ hocvan2 } & Hoàn thành cấp 2 = 1 \\
\hline & & Khác $=0$ \\
\hline & hocvan3 & $\begin{array}{l}\text { Hoàn thành cấp } 3=1 \\
\text { Khác }=0\end{array}$ \\
\hline Giới tính chủ hộ & Nam/Nữ & $\mathrm{Nam}=1 ; 0=\mathrm{Nu} \tilde{u}$ \\
\hline Vay vốn sản xuất & Vayvon & Có $=1$, Không $=0$ \\
\hline Địa bàn nghiên cứu & Diaban & Cà Mau=1, Sóc Trăng=0 \\
\hline Xâm nhập mặn & Nhapman & Có=1, Không=0 \\
\hline
\end{tabular}

Nguồn: Tác giả tổng hơp

\subsection{Số liệu}

Số liệu được thu thập bằng phương pháp phỏng vấn trực tiếp hộ trồng lúa ở hai tỉnh Cà Mau và Sóc Trăng. Phương pháp chọn mẫu ngẫu nhiên được sử dụng để xác định cỡ mẫu, trong đó các hộ trồng lúa chuyên canh và lúa kết hợp được chọn trong cùng một đơn vị địa bàn trong một huyện đảm bảo tỉ lệ cân bằng. Cụ thể, 229 hộ sản xuất lúa chuyên canh và lúa kết hợp phân bổ tương đồng ở các huyện Trần Đề, Kế Sách, Mỹ Xuyên, Châu Thành, Thạnh Trị, Mỹ Tú, Long Phú, thị xã Vĩnh Châu và thị xã Ngã Năm của tỉnh Sóc Trăng và tại các huyện Thới Bình,

\section{Bảng 2. Tỉ lệ các mô hình lúa chuyên canh và lúa kết hợp ở Sóc Trăng và Cà Mau}

\begin{tabular}{llrr}
\hline Mô hình & Mô tả & Số hộ & Tỷ trọng (\%) \\
\hline Lúa chuyên canh & Lúa 2 vụ hoặc 3 vụ & 96 & 41,74 \\
\hline \multirow{3}{*}{ Lúa kết hợp } & Lúa - Tôm & 43 & 18,78 \\
& Lúa - Cá & 6 & 2,62 \\
& Lúa - Màu & 84 & 36,68 \\
\hline Tổng & & 229 & 100,00 \\
\hline
\end{tabular}

Nguồn: Tổng hợp tù kết quả điều tra, 2019

Đặc điểm của chủ hộ theo mô hình canh tác được trình bày ở Bảng 3 . Trong đó, chủ hộ trông lúa chuyên canh có trình độ từ cấp 3 trở lên chiếm tỉ lệ
$\mathrm{H}_{2 \mathrm{a}}$ : Xác suất chuyển đổi mô hình canh tác lúa chuyên canh sang lúa kết hợp phụ thuộc vào xâm nhập mặn;

Bảng 2. Mô tả biến và dấu kỳ vọng của các biến trong mô hình.
Trần Văn Thời và U Minh của tỉnh Cà Mau được chọn để khảo sát.

\section{KẾT QUẢ VÀ THẢO LUẬN}

4.1. Đặc điểm các mô hình sản xuất lúa chuyên canh và lúa kết hợp ở Cà Mau và Sóc Trăng

Tỉ lệ phân bổ các mô hình canh tác lúa được trình bày ở Bảng 2 . Trong đó, tỉ lệ hộ trồng lúa chuyên canh chiếm tỉ lệ $41,7 \%$ và hộ trồng lúa kết hợp chiếm tỉ lệ $58,3 \%$. Các mô hình lúa màu và lúa cá chiếm tỉ lệ cao hơn so với mô hình lúa tôm trong nhóm các mô hình lúa kết hợp ở địa bàn nghiên cứu. 
khác biệt đáng kể giữa hai mô hình. Nhìn chung, chủ hộ trồng lúa điển hình ở hai tỉnh là nam và có trình hộ học vấn ở mức cấp trung học phổ thông chiếm tỉ lệ chủ yếu.

Bảng 3. Trình độ học vấn và giới tính của chủ hộ theo mô hình sản xuất

\begin{tabular}{|c|c|c|c|c|c|c|}
\hline & \multicolumn{2}{|c|}{ Lúa chuyên canh } & \multicolumn{2}{|c|}{ Lúa kết hợp } & \multicolumn{2}{|c|}{ Sóc Trăng và Cà Mau } \\
\hline & Tần suất & Tỷ trọng (\%) & Tần suất & Tỷ trọng (\%) & Tần suất & Tỷ trọng (\%) \\
\hline \multicolumn{7}{|l|}{ Trình độ học vấn } \\
\hline Mù chữ & 26 & 25,53 & 30 & 22,56 & 56 & 24,45 \\
\hline Học vấn cấp 1 & 38 & 40,43 & 44 & 33,08 & 82 & 35,81 \\
\hline Học vấn cấp 2 & 25 & 26,60 & 41 & 30,83 & 66 & 28,82 \\
\hline Học vân câp 3 & 4 & 4,26 & 16 & 12,03 & 20 & 8,73 \\
\hline Đại học & 3 & 3,19 & 2 & 1,50 & 5 & 2,18 \\
\hline \multicolumn{7}{|l|}{ Giới tính chủ hộ } \\
\hline Nam & 89 & 92,71 & 118 & 88,7 & 207 & 90,39 \\
\hline Nữ & 7 & 7,29 & 15 & 11,3 & 22 & 9,61 \\
\hline
\end{tabular}

Nguồn: Tổng hợp tù̀ kết quả điều tra, 2019

Đặc điểm vay vốn và đặc điểm sản xuất của hộ theo mô hình canh tác được trình bày ở Bảng 4 và Bảng 5. Trong đó, chủ hộ trồng lúa chuyên canh có

Bảng 4. Hiện trạng vay vốn theo mô hình sản xuất

\begin{tabular}{lrrrrrr}
\hline & \multicolumn{2}{c}{ Lúa chuyên canh } & \multicolumn{2}{c}{ Lúa kết hợp } & \multicolumn{2}{c}{ Sóc Trăng và Cà Mau } \\
\hline & Tần số & Tỷ trọng (\%) & Tần số & Tỷ trọng (\%) & Tần số & Tỷ trọng (\%) \\
\hline Có vay vốn & 93 & 96,88 & 95 & 71,43 & 188 & 82,10 \\
Không vay vốn & 3 & 3,13 & 38 & 28,57 & 41 & 17,90 \\
\hline Tổng & 96 & 100,00 & 133 & 100,00 & 229 & 100,00 \\
\hline
\end{tabular}

Nguồn: Tổng hợp tì kết quả điều tra, 2019

Bảng 5. Đặc điểm của hộ trồng lúa theo mô hình canh tác

\begin{tabular}{lrrrrrr}
\hline \multirow{2}{*}{ Mô hình } & \multicolumn{3}{c}{ Lúa chuyên canh } & \multicolumn{3}{c}{ Lúa kết hợp } \\
\cline { 2 - 7 } & Trung bình & Cao nhất & Thấp nhất & Trung bình & Cao nhất & Thấp nhất \\
\hline Tuổi chủ hộ & 52 & 81 & 24 & 52,07 & 86 & 26 \\
Số nhân khẩu & 4,5 & 9 & 1 & 4,38 & 10 & 2 \\
Lao động chính & 3,74 & 7 & 1 & 3,65 & 7 & 2 \\
Diện tích đất & 17,62 & 25 & 1 & 12,86 & 89 & 1 \\
\hline
\end{tabular}

Nguồn: Tổng hợ tù kết quả điều tra, 2019

Bảng 6. Đặc điểm của hộ trồng lúa theo địa bàn

\begin{tabular}{lrrrrrr}
\hline \multirow{2}{*}{ Mô hình } & \multicolumn{3}{c}{ Sóc Trăng } & \multicolumn{3}{c}{ Cà Mau } \\
\cline { 2 - 7 } \multicolumn{1}{c}{ Tuối chủ hộ } & Trung bình & Cao nhất & Thấp nhất & Trung bình & Cao nhất & Thấp nhất \\
Số nhân khẩu & 53 & 86 & 29 & 49,51 & 71 & 24 \\
Lao động chính & 4,47 & 9 & 1 & 4,34 & 10 & 2 \\
Diện tích đất & 3,76 & 7 & 1 & 3,5 & 7 & 2 \\
\hline
\end{tabular}

Nguồn: Tổng hợp tù kết quả điều tra, 2019

Đặc điểm tuổi của chủ hộ, số nhân khẩu, lao động chính và diện tích đất theo mô hình canh tác và theo địa bàn được trình bày ở Bảng 5 và Bảng 6 . Độ tuổi trung bình của chủ hộ trong khoảng 52 tuổi và không có sự chênh lệch tuổi tác của chủ hộ giữa hai mô hình canh tác. Ở mô hình chuyên canh lúa, tỉ lệ vay vốn là $97 \%$ so với tỉ lệ vay vốn $71 \%$ của nhóm hộ trồng lúa kết hợp. Nhìn chung, tỉ lệ hộ có vay vốn để sản xuất chiếm tỉ lệ $82 \%$ trên địa bàn nghiên cứu. 
độ tuổi, số nhân khẩu, và số người lao động tạo thu nhập không khác biệt đáng kể giữa các mô hình sản xuất cũng như giữa hai tỉnh Cà Mau và Sóc Trăng. Trong khi đó, hộ trồng lúa chuyên canh có diện tích đất canh tác bình quân là 1,762 ha, cao nhất là 25 ha, thấp nhất là 0,1 ha. So với mô hình lúa kết hợp, diện tích đất, số nhân khẩu và số lao động chính tạo thu nhập có phần ít hơn, tương ứng. Ngoài ra, diện tích đất bình quân của hộ trồng lúa ở Sóc Trăng lớn hơn so với diện tích đất của hộ trồng lúa ở Cà Mau.
Thực trạng xâm nhập mặn theo địa bàn và theo mô hình canh tác lúa được trình bày ở Bảng 7 . Trong đó, hộ trồng lúa bị ảnh hưởng bởi xâm nhập mặn ở Sóc Trăng chiếm tỉ lệ cao hơn so với tỉ lệ hộ trồng lúa bị xâm nhập mặn ở Cà Mau. Cụ thể, hơn 19\% hộ trồng lúa ở Sóc Trẳng chịu ảnh hưởng bởi xâm nhập mặn so với hơn $41 \%$ hộ trồng lúa ở Cà Mau. Xét ảnh hưởng của xâm nhập mặn đến mô hình canh tác, hơn $96 \%$ hộ trồng lúa chuyên canh chịu ảnh hưởng của xâm nhập mặn so với tỉ lệ chỉ $61 \%$ của hộ trồng lúa kết hợp bị ảnh hưởng bởi xâm nhập mặn.

Bảng 7. Xâm nhập mặn theo mô hình sản xuất và theo địa bàn

\begin{tabular}{lcccccccr}
\hline \multirow{2}{*}{$\begin{array}{l}\text { Tình hình xâm } \\
\text { nhập mặn }\end{array}$} & \multicolumn{2}{c}{ Lúa kết hợp } & \multicolumn{2}{c}{ Lúa chuyên canh } & \multicolumn{2}{c}{ Cà Mau } & \multicolumn{2}{c}{ Sóc Trăng } \\
\cline { 2 - 9 } & $\begin{array}{r}\text { Tần } \\
\text { suất }\end{array}$ & $\begin{array}{r}\text { Tỉ lệ } \\
\mathbf{( \% )}\end{array}$ & $\begin{array}{c}\text { Tần } \\
\text { suất }\end{array}$ & $\begin{array}{r}\text { Tỉ lệ } \\
\mathbf{( \% )}\end{array}$ & $\begin{array}{r}\text { Tần } \\
\text { suất }\end{array}$ & $\begin{array}{r}\text { Tỉ lệ } \\
\mathbf{( \% )}\end{array}$ & $\begin{array}{r}\text { Tần } \\
\text { suất }\end{array}$ & $\begin{array}{r}\text { Tỉ lệ } \\
(\%)\end{array}$ \\
\hline Có & 81 & 60,9 & 93 & 96,9 & 29 & 41,4 & 145 & 91,2 \\
Không & 52 & 39,1 & 3 & 3,1 & 41 & 58,6 & 14 & 8,8 \\
\hline Tồng & 133 & 100,0 & 96 & 100,0 & 70 & 100,0 & 159 & 100,0 \\
\hline
\end{tabular}

Nguồn: Tổng hợp tù kết quả điều tra, 2019

4.2. Các yếu tố ảnh hưởng đến quyết định chuyển đổi mô hình canh tác

Bảng 8 trình bày kết quả ước lượng các yếu tố ảnh hưởng đến quyết định chuyển đổi mô hình canh tác lúa. Các giá trị kiểm định cho thấy các yếu tố trong mô hình ước lượng phù hợp để giải thích cho quyết định chuyển đổi của nông hộ. Trong đó, giá trị $\chi^{2}$ xấp xỉ 0 , hệ số Pseudo-R $\mathrm{R}^{2}$ là 0,223 và tỷ lệ dự đoán đúng của mô hình là $71,18 \%$. Các biến có ý nghĩa giải thích cho quyết định chuyển đổi mô hình sản xuất của hộ trồng lúa bao gồm diện tích đất, vay vốn, địa bàn, và xâm nhập mặn.

Bảng 8. Kết quả ước lượng các yếu tố ảnh hưởng đến quyết định lựa chọn mô hình

\begin{tabular}{|c|c|c|c|c|}
\hline \multirow{2}{*}{ Biến độc lập } & Hệ số ước lượng & Sai số chuẩn & Giá trị p & Tác động biên \\
\hline & $(\beta)$ & (s.e) & (p-value) & $(d y / d x)$ \\
\hline Tuổi & 0,943 & 0,684 & 0,168 & 0,171 \\
\hline Giới tính & $-0,526$ & 0,528 & 0,319 & $-0,095$ \\
\hline Học vấn cấp 1 & $-0,707$ & 0,646 & 0,273 & $-0,127$ \\
\hline Học vấn cấp 2 & $-0,737$ & 0,622 & 0,236 & $-0,133$ \\
\hline Học vấn cấp 3 & $-0,323$ & 0,636 & 0,612 & $-0,058$ \\
\hline Số nhân khẩu & $-0,157$ & 0,197 & 0,425 & $-0,028$ \\
\hline Lao động chính & 0,174 & 0,260 & 0,503 & 0,031 \\
\hline Diện tích & $-0,296^{*}$ & 0,175 & 0,091 & $-0,054$ \\
\hline Vay vốn sản xuất & $-1,616^{* *}$ & 0,631 & 0,011 & $-0,292$ \\
\hline Địa bàn & $0,453^{*}$ & 0,232 & 0,052 & 0,082 \\
\hline Xâm nhập mặn & $2,387 * * *$ & 0,685 & 0,000 & 0,431 \\
\hline Hằng số & $-4,890$ & 3,127 & 0,118 & . \\
\hline Số quan sát (N) & & 229 & & \\
\hline Giá trị kiểm định $\chi^{2}$ & & 0,000 & & \\
\hline Hệ số Pseudo-R² & & 0,2231 & & \\
\hline Tỉ lệ dự báo đúng (\%) & & 71,18 & & \\
\hline
\end{tabular}

Nguồn: Số liệu khảo sát năm 2018-2019

Ghi chú: ***, và *** chỉ múc ý nghĩa 10\%, 5\% và 1\%, tuoong úng

Biến diện tích (ở dạng logarit tự nhiên) có ảnh hưởng đến chuyển đổi mô hình canh tác có mức ý nghĩa $10 \%$ và tương quan nghịch với xác suất chuyển đổi mô hình sản xuất lúa kết hợp. Hệ số tác 
động biên của diện tích là $-0,054$; có nghĩa là nếu hộ có diện đất tăng $1 \%$ thì xác suất chuyển đổi giảm 0,54 điểm phần trăm. Như vậy, khi diện tích đất tăng lên, hộ trồng lúa thường có xu hướng ít chuyển đồi mô hình hơn. Kết quả này cho phép bác bỏ giả thuyết $\mathrm{H}_{10}$, như vậy quyết định chuyển đổi mô hình canh tác lúa kết hợp phù hợp mục tiêu đối đa hóa lợi ích dựa vào mô hình Ricardian và tương đồng với Seo and Mendelsohn (2008). Mối tương quan nghịch hàm ý rằng những hộ có diện tích sản xuất lớn thường khó thực hiện chuyển đổi mô hình do rủi ro chuyển đổi cao, trong khi đó hộ trồng lúa càng có diện tích đất sản xuất ít, sẽ không đủ điều kiện tạo ra thu nhập cho gia đình và để có sinh kế ổn định, họ có thêm động lực chuyển đổi cơ cấu sản xuất với hy vọng sẽ có được thu nhập cao hơn trong tương lai.

Biến xâm nhập mặn có tương quan thuận với xác suất chuyển đổi từ lúa chuyên canh sang lúa kết hợp ở mức ý nghĩa là $1 \%$. Hệ số tác động biên của xâm nhập mặn là 0,431 có nghĩa là hộ trồng lúa trong điều kiện bị ảnh hưởng xâm nhập mặn có xác suất chuyển đổi cao hơn hộ trồng lúa trong điều kiện không xâm nhập mặn 43,1 điểm phần trăm. Kết quả này cho phép bác bỏ giả thuyết $\mathrm{H}_{20}$, và cho kết luận rằng xâm nhập mặn là điều kiện tự nhiên ảnh hưởng trực tiếp đến khả năng chuyển đổi mô hình canh tác lúa. Bởi vì, lúa bị nhập mặn không cho năng suất cao, vì vậy hộ phải linh hoạt chuyển đổi mô hình sản xuất, tìm các mô hình lúa kết hợp để khai thác tốt nhất nguồn lực đất đai thích nghi với điều kiện ngập mặn. Kết quả này củng cố kết luận của Huong et al. (2019) cho rằng biến đổi khí hậu có ảnh hưởng đến khả năng chuyển đổi mô hình của nông dân ở miền Bắc và tương đồng với kết quả nghiên cứu của $\mathrm{Seo}$ and Mendelsohn (2008) ở Nam Mỹ.

Các biến kiểm soát có ý nghĩa gồm vay vốn và địa bàn. Biến vay vốn có ảnh hưởng đến chuyển đổi mô hình canh tác có mức ý nghĩa $5 \%$ và tương quan nghịch với xác suất chuyển đổi mô hình sản xuất lúa kết hợp. Hệ số tác động biên của diện tích là $-0,292$ có nghĩa là trong điều kiện hộ có vay vốn thì có xác suất chuyển đổi giảm 29,2 điểm phần trăm. Trong khi đó, biến địa bàn có ảnh hưởng đến quyết định chuyển đổi mô hình canh tác ở mức ý nghĩa $10 \%$ và tương quan thuận với xác suất chuyển đổi mô hình. Kết quả cho thấy các hộ trồng lúa ở địa bàn tỉnh Cà Mau có xác suất chuyển đồi mô hình lúa kết hợp nhiều hơn các hộ trồng lúa ở Sóc Trăng. Cụ thể, xác suất chuyển đổi mô hình của hộ trồng lúa ở Cà Mau cao hơn xác suất chuyển đổi mô hình hộ trồng lúa ở Sóc Trăng là 8,2 điểm phần trăm. Kết quả này phù hợp với thực tế rằng địa bàn Cà Mau có vị trí địa lý và điều kiện tự nhiên không chỉ phù hợp với mô hình chuyên canh lúa mà còn có thế mạnh về nuôi trồng thủy sản trên đất lúa hoặc các mô hình trồng rau màu. Điều kiện này chính là nền tảng giúp cho Cà Mau dễ dàng thực hiện chuyển đổi hơn so với Sóc Trăng.

Tóm lại, kết quả ước lượng cho thấy có bốn yếu tố ý nghĩa bao gồm diện tích, vay vốn, địa bàn, và ngập mặn. Trong đó, biến ngập mặn là yếu tố quan trọng nhất tác động trực tiếp đến quyết định chuyển đổi mô hình sản xuất từ mô hình sản xuất lúa độc canh sang mô hình lúa kết hợp. Kết quả này phản ánh thực tế rằng khi có hiện tượng xâm nhập mặn vào ruộng lúa, hộ trồng lúa đã có quyết định chuyển đổi mô hình để thích ứng với điều kiện biến đổi khí hậu hiện nay.

\section{KẾT LUẬn VÀ HÀM Ý CHÍNH SÁCH}

Diễn biến xâm nhập mặn có ảnh hưởng rất lớn đến hộ trồng lúa ở các tỉnh ven biển ở ĐBSCL, trong đó Sóc Trăng và Cà Mau là hai tỉnh chịu ảnh hưởng rõ rệt nhất. Các mô hình canh tác trên nền đất lúa chiếm đa số với hơn $45 \%$ diện tích lúa bị ảnh hưởng bởi xâm nhập mặn tính đến năm 2020. Trong đó, nhiều mô hình cụ thể như lúa cá, lúa tôm, và lúa màu được ghi nhận trên địa bàn của hai tỉnh bên cạnh mô hình chuyên canh cây lúa. Xu hướng chuyển đổi từ mô hình trồng lúa chuyên canh 2 vụ và 3 vụ sang mô hình lúa kết hợp trong điều kiện xâm nhập mặn được ghi nhận với tỉ lệ khá cao. Kết quả nghiên cứu cho thấy quyết định lựa chọn mô hình sản xuất lúa chuyên canh sang mô hình lúa kết hợp của hộ trồng lúa ở tỉnh Sóc Trăng và Cà Mau bao gồm: diện tích đất, vay vốn, địa bàn và xâm nhập mặn. Trong đó, nhập mặn là yếu tố quan trọng nhất tác động trực tiếp đến quyết định chuyển đổi mô hình sản xuất từ lúa chuyên canh sang lúa kết hợp thủy sản. Kết quả này phù hợp với xu hướng chuyền dịch cơ cấu nông nghiệp của tỉnh toàn vùng ĐBSCL.

Lựa chọn mô hình sản xuất lúa chuyên canh và mô hình lúa kết hợp phụ thuộc rất lớn vào điều kiện xâm nhập mặn do tự nhiên gây ra. Vì vậy, để các mô hình sản xuất lúa kết hợp phát triển bền vững và mang lại hiệu quả kinh tế cao, các hộ trồng lúa có định hướng chuyển đổi mô hình cần quan tâm đến các vấn đề sau: (i) cần tích cực chuyển đổi phương thức canh tác, bao gồm: thay đổi giống lúa chịu mặn, chịu phèn cao để không chỉ ứng phó với xâm nhập mặn mà còn có thể thích nghi được với vùng đất ĐBSCL vốn bị nhiễm phèn; điều chỉnh lịch thời vụ để phù hợp với tình hình, giảm thiểu tối đa ảnh hưởng của khô hạn, xâm nhập mặn; (ii) rửa mặn kỹ cho đất nhất là sau vụ thủy sản, đảm bảo đất khỏe để 
bắt đầu gieo sạ cho vụ lúa sau; (iii) cân nhắc kỹ lưỡng các mô hình canh tác lúa kết hợp dựa vào nguồn vốn của hộ đảm bảo phù hợp với khả năng sản xuất, tránh các hình thức đòi hỏi kỹ thuật cũng như mức đầu tư vượt tầm kiểm soát dẫn đến chi phí cao, hiệu quả thấp, rủi ro cao; và (iv) không ngừng học hỏi, cập nhật kiến thức, nâng cao trình độ sản xuất đặc biệt đối với những hộ chưa có hoặc ít kinh nghiệm trong việc nuôi thủy sản, tăng cường ứng dụng khoa học kỹ thuật, công nghệ tiên tiến vào sản xuất để thu được hiệu quả cao hơn.

Bên cạnh đó, nhà nước và chính quyền địa phương cần: (i) hỗ trợ tập huấn các mô hình sản xuất lúa kết hợp cho nông dân; (ii) quy hoạch lại vùng sản xuất phù hợp với điều kiện tự nhiên, quan tâm theo dõi việc chuyển đổi cũng như hiệu quả của mô hình, khuyến cáo các hình thức nuôi thủy sản phù hợp với khả năng tài chính, trình độ học vấn, kinh nghiệm sản xuất của từng nông hộ; và (iii) hỗ trợ nghiên cứu về chuỗi giá trị lúa gạo, thủy sản để tìm ra giải pháp nâng cao giá trị gia tăng, hướng đến sự phát triển ổn định và bền vững trong tương lai.

\section{LỜI CẢM TẠ}

Đề tài này được tài trợ bởi Dự án Nâng cấp Trường Đại học Cần Thơ VN14-P6 bằng nguồn vốn vay ODA từ chính phủ Nhật Bản.

\section{TÀI LIÊU THAM KHẢO}

Hà Anh. (2016). Khẩn cấp ứng phó với tình hình hạn hán, xâm nhập mạn đang nghiêm trọng tại đồng bằng sông Cửu Long.

https://dangcongsan.vn/khuyen-nong-huongtoi-su-phat-trien-ben-vung/tin-tuc/khan-capung-pho-voi-tinh-hinh-han-han-xam-nhapman-dang-nghiem-trong-tai-dong-bang-songcuu-long-376173.html

Thanh Phong. (2020). Đơt hạn, mạn nghiêm trọng nhất trong lịch sử Đồng bằng sông Cửu Long. https://nhandan.com.vn/chuyen-lam-an/dothan-man-nghiem-trong-nhat-trong-lich-sudbscl-475180/

Cameron, A. C., \& Trivedi, P. K. (2010). Microeconometrics using stata, Vol. 2. College Station TX: Stata press.

Đặng Thanh Phú. (2010). Phân tích hiệu quả sản xuất lúa trong mô hình lúa - tôm luân canh vùng ven biển $Đ B S C L$ (Luận văn Thạc sĩ). Trường Đại học Cần Thơ.

Đoàn Thu Hà. (2014). Đánh giá mức độ tổn thương do biến đồi khí hậu đến cấp nước nông thôn. Tạp chí Khoa học Thủy lợi và Kỹ thuật môi trường, 49, 34 - 40.
Gbetibouo, G. A., \& Hassan, R. M. (2005). Measuring the economic impact of climate change on major South African field crops: a Ricardian approach. Global and Planetary Change, 47(2-4), 143-152.

Gregorio, G. B., Senadhira, D., \& Mendoza, R. D. (1997). Screening rice for salinity tolerance. IRRI Discussion Paper Series No. 22. Manila (Philippines): International Rice Research Institute.

Hoang, T. M. L., Tran, T. N., Nguyen, T. K. T., Williams, B., Wurm, P., Bellairs, S., \& Mundree, S. (2016). Improvement of salinity stress tolerance in rice: challenges and opportunities. Agronomy, 6(4), 54.

Huong, N. T. L., Bo, Y. S., \& Fahad, S. (2019). Economic impact of climate change on agriculture using Ricardian approach: A case of northwest Vietnam. Journal of the Saudi Society of Agricultural Sciences, 18(4), 449 - 457.

Greene, W. H. (2012). Econometric Analysis, $7^{\text {th }}$ Ed. Boston: Pearson Education.

Lâm Huôn. (2010). Anh hưởng của xâm nhập mặn đến đời sống và sản xuất của các nhóm hộ tại vùng ven biển tỉnh Sóc Trăng (Luận văn Thạc sĩ). Trường Đại học Cần Thơ.

Lippert, C., Krimly T., \& Aurbacher J. (2009). A Ricardian analysis of the impact of climate change on agriculture in Germany. Climate Change, 97(3-4), $593-610$.

McFadden, D. (1974). Conditional logit analysis of qualitative choice behavior. In Zarembka, Paul, ed., Frontiers in Econometrics, Academic Press: New York.

Mendelsohn, R., Nordhaus, W. D., \& Shaw, D. (1994). The impact of global warming on agriculture: a Ricardian analysis. The American economic review, 84(4), $753-771$.

Nguyễn Bách Khoa. (2015). Đánh giá tính tổn thương của nông dân vùng Đồng bằng sông Cửu Long dưới tác động của lũ và xâm nhập mặn (Luận văn Thạc sĩ). Trường Đại học Cần Thơ.

Nguyễn Thanh Giàu. (2009). So sánh hiệu quả kinh tế của mô hình 2 vu lúa - 1 vu đậu nành và mô hình 3 vu lúa ở hai xã Thành Lợi và Tân Bình, tỉnh Vĩnh Long (Luận văn Thạc sĩ). Trường Đại học Cần Thơ.

Nguyễn Thị Hồng Điệp, Danh Huội và Nguyễn Trọng Cần. (2017). Đánh giá tác động của xâm nhập mặn do biến đổi khí hậu trên hiện trạng canh tác lúa tại tỉnh Sóc Trăng. Tạp chi khoa hoc Truờng Đại họ Cần Tho. Số chuyên đề: Môi trường và Biến đổi khí hậu 2017(2), 137 - 143. 
Nguyễn Vương Quốc. (2015). Đánh giá hiệu quả kinh tế các mô hình luân canh màu trên nền đất lúa tại địa bàn quận Bình Thủy thành phố Cần Tho (Luận văn Thạc sĩ). Trường Đại học Cần Thơ.

Phạm Thanh Vũ, Vương Tuấn Huy, Lê Quang Trí \& Phan Hoàng Vũ. (2013). Sự thay đổi mô hình canh tác theo khả năng thích ứng của người dân tại các huyện ven biển tỉnh Sóc Trăng và Bạc Liêu. Tạp chi Khoa học Trường Đại hoc Cần Tho, 26, 46 - 54.

Quan Minh Nhựt \& Trần Thị Thu Hiền. (2014). Đánh giá hiệu quả sản xuất của mô hình luân canh lúa - mè đen - lúa, quận Ô Môn, thành phố Cần Thơ. Tạp chi Khoa học Truờng Đại hoc Cần Tho, 31, 24 - 30.

Seo, S. N., \& Mendelsohn, R. (2008). An analysis of crop choice: Adapting to climate change in South American farms. Ecological economics, 67(1), 109 - 116.

Trần Hũu Phúc, Phạm Thị Pari, Nguyễn Duy Cần \& Nguyễn Văn Khang. (2007). Đánh giá hiệu quả kinh tế giữa các mô hình canh tác trên nền đất lúa trong vùng ngọt hóa Gò Công. Tap chí khoa hoc Trường Đại học Cần Tho, 12, 346 - 355. 